\title{
Remoção de corpo estranho da via aérea de criança por broncoscopia através de traqueotomia ou traqueostomia
}

\author{
Bronchoscopic removal of foreign body from airway \\ through tracheotomy or tracheostomy \\ José C. Fraga ${ }^{1}$, Alexandra F. Pires ${ }^{2}$, Marcia Komlos ${ }^{2}$, \\ Eliziane E. Takamatu ${ }^{3}$, Luciano G. Camargo ${ }^{3}$, Fábio H.Á. Contelli ${ }^{3}$
}

\section{Resumo}

Objetivo: a maioria dos corpos estranhos aspirados para a via aérea é removida através de endoscopia respiratória. Em situações raras, a retirada deste material tem que ser realizada sob controle endoscópico, através de traqueotomia ou traqueostomia. A seguir, relatamos casos de crianças cuja remoção de corpos estranhos aspirados para a via aérea foi realizada por abertura traqueal.

Descrição: revisão retrospectiva de prontuários, com relato de três crianças que aspiraram corpos estranhos para a via aérea. A primeira apresentou ruptura da cânula de traqueostomia, com aspiração da porção distal da mesma. Foi realizada remoção endoscópica através do traqueostoma. A segunda aspirou tampa de caneta, que não conseguia ser removida endoscopicamente, pois a mesma trancava e não passava na região subglótica. Foi realizado, então, traqueotomia cervical e remoção do corpo estranho sob controle endoscópico. A terceira apresentou corpo estranho aspirado para o brônquio principal esquerdo (palito de madeira), que foi removido através de broncoscopia, realizada pelo orifício da traqueostomia. Todas as crianças toleraram o procedimento endoscópico, com remoção do corpo estranho. No paciente em que foi realizada traqueotomia, a traquéia foi suturada após retirada do corpo estranho, não havendo necessidade de realização de traqueostomia. Nas crianças com traqueostomia prévia, a mesma foi recolocada após a retirada do corpo estranho.

Comentários: uma minoria dos corpos estranhos aspirados para a via aérea de criança não pode ser removido somente por endoscopia. Quando o corpo estranho é demasiadamente largo que não passa na região subglótica, ou pontiagudo que possa traumatizar a via aérea, a remoção pode ser realizada por endoscopia, através de traqueotomia ou traqueostomia.

J Pediatr (Rio J) 2003;79(4):369-72: corpo estranho via aérea, traqueotomia, broncoscopia.

\begin{abstract}
Objective: most foreign bodies in the airway are removed by respiratory endoscopy. Rarely, the removal of the foreign body has to be performed through endoscopic control by tracheotomy or tracheostomy. This article reports three cases of foreign body removal in children performed by tracheal opening.

Description: retrospective review of records with report of three cases of children who aspirated foreign bodies into the airway. In the first case, there was rupture of the tracheostomy tube, with aspiration of its distal portion. Endoscopic removal was performed by tracheostomy. The second child aspirated a pen cap. It could not be removed by endoscopy because it would not pass through the subglottic region. Cervical tracheotomy was performed and the foreign body was removed with endoscopic control. In the last case, the foreign body was in the left main bronchus. It was removed by bronchoscopy through tracheostomy opening. All children presented good outcome after the endoscopic procedure. The trachea of the patient submitted to tracheotomy was sutured after the foreign body removal. Tracheostomy was not necessary. In the children with previous tracheostomy, the tube was put back after the foreign body removal.
\end{abstract}

Comments: most foreign bodies in the airway of children can be removed by endoscopy. When the foreign body is too large to pass through the subglottic region, or so sharp that it can injure the airway, the use of tracheotomy or tracheostomy is indicated.

J Pediatr (Rio J) 2003;79(4):369-72: airway foreign body, tracheotomy, bronchoscopy.

1. Professor Adjunto Cirurgia Pediátrica da Faculdade de Medicina e do Curso de Pós-graduação em Medicina: Cirurgia - Universidade Federal do Rio Grande do Sul (UFRGS). Cirurgião Pediátrico do Setor de Cirurgia Torácica Infantil do Hospital de Clínicas de Porto Alegre (HCPA).

2. Acadêmica da Faculdade de Medicina da UFRGS.

3. Médico(a) Residente de Cirurgia Pediátrica do HCPA.

Trabalho apresentado no XXIII Congresso Brasileiro de Cirurgia Pediátrica, realizado em Goiás, de 3 a 7 de novembro de 2002.

Artigo submetido em 12.12.02, aceito em 26.03.03. 


\section{Introdução}

A maioria dos corpos estranhos (CE) aspirados para a via aérea da criança é removido através de endoscopia respiratória, com instrumentos endoscópicos introduzidos através da boca. Entretanto, raramente, quando o CE for muito grande que não consiga ultrapassar a região subglótica, ou que seja pontiagudo com riscos de perfuração das vias aéreas, a retirada do CE pode ser feita através de abertura traqueal.

Relatamos a seguir três casos clínicos de crianças com aspiração de CE para a via respiratória nos quais a remoção foi feita através de instrumento endoscópico, introduzido através de traqueostomia ou traqueotomia.

\section{Descrição de casos}

\section{Caso 1}

F.P.P., 6 anos, feminina, com diagnóstico de síndrome de hipoventilação alveolar central idiopática ("Mal de Ondina"), tendo sido traqueostomizada ainda no período neonatal por apnéia e necessidade de ventilação mecânica prolongada. Durante internação em unidade de tratamento intensivo, apresentou disfunção ventilatória súbita, após saída acidental da cânula de traqueostomia de PVC (Portex $\left.{ }^{\circledR}\right)$. Avaliação imediata mostrou que a cânula havia quebrado na junção do tubo, com a placa horizontal utilizada para fixação da cânula no pescoço, tendo ocorrido aspiração da porção distal da mesma. Radiografia de tórax confirmou que parte tubular da cânula estava localizada na traquéia distal. Criança foi submetida à endoscopia respiratória, com broncoscópio rígido introduzido através do traqueostoma e remoção de porção da cânula de traqueostomia aspirada. Paciente teve ótima evolução pós-endoscópica.

\section{Caso 2}

A.S.J., 8 anos, masculino, asmático, encaminhado ao nosso hospital por disfunção respiratória aguda, com suspeita de aspiração de vômitos. Apresentou grave dificuldade respiratória, com necessidade de intubação traqueal. $\mathrm{Na}$ internação apresentava radiografia de tórax com atelectasia de todo o pulmão direito. Fibrobroncoscopia realizada na própria UTI, através do tubo endotraqueal, mostrou CE inorgânico de coloração azulada e aspecto plástico no óstio do brônquio principal direito. O paciente então se submeteu a broncoscopia rígida no Centro Cirúrgico Ambulatorial do HCPA, sob anestesia geral, utilizando-se broncoscópio rígido com ótica de $0^{\circ}$ conectada a equipamento de vídeo. Observou-se que o CE ocluía completamente o brônquio principal direito. Este foi apreendido com pinça endoscópica e tracionado. O CE vinha facilmente até a região subglótica, mas não conseguia transpor esta região. Como o CE na traquéia obstruía a ventilação e provocava dessaturação de oxigênio, o mesmo foi empurrado para o brônquio direito com o auxílio do broncoscópio. A criança foi ventilada, e, após estabilização da ventilação, realizada nova tentativa de remoção do CE. Após a terceira tentativa sem sucesso, sendo que nesta última o paciente apresentou grave dessaturação de oxigênio, com arritmia cardíaca, optou-se pela colocação de tubo endotraqueal e realização de traqueotomia. Através de incisão cervical, foi exposta a traquéia e preparada para ser aberta. $\mathrm{O}$ tubo traqueal foi então removido, e o broncoscópio novamente inserido na via aérea. Pinça endoscópica tracionou o $\mathrm{CE}$ até a região subglótica. Neste instante foi realizada abertura transversa da traquéia, no terceiro anel traqueal, e remoção do CE através da traqueotomia com auxílio de pinça hemostática. Tratava-se de uma tampa superior de caneta. Após estabilização ventilatória da criança, o broncoscópio foi removido, sendo realizada intubação nasotraqueal. A traquéia foi a seguir fechada com pontos separados de PDS 5-0, seguindo-se o fechamento da incisão cervical por planos. Foi realizado fechamento da abertura cervical, sem colocação de cânula de traqueostomia. A criança permaneceu com tubo traqueal durante três dias, quando foi extubada na UTI pediátrica. Permaneceu com estridor e leve tiragem intercostal durante dois dias, melhorando a seguir. $\mathrm{Na}$ revisão, um mês após o procedimento, mostrava ausência de sintomas respiratórios, com radiografia de tórax mostrando ambos os pulmões expandidos.

\section{Caso 3}

C.S., 4 anos, feminina, portadora de traqueostomia devido à estenose subglótica grave, decorrente de intubação prolongada no passado. Consultou na emergência por febre, taquipnéia e secreção amarelada pela traqueostomia. Ao exame, apresentava miíase no traqueostoma, e radiografia de tórax com broncopneumonia. Foi iniciado tratamento com antibióticos, e, sob anestesia geral, realizada limpeza do traqueostoma, com remoção de inúmeras larvas. Endoscopia respiratória, com broncoscópio rígido introduzido pelo traqueostoma, mostrou larvas na traquéia intratorácica e corpo estranho (palito de madeira) no brônquio principal esquerdo. Os materiais estranhos foram removidos com pinça endoscópica introduzida por dentro do broncoscópio. A criança apresentou boa recuperação, tendo sido posteriormente encaminhada para o Serviço de Proteção da Criança.

\section{Discussão}

A presença de material estranho na via aérea da criança continua sendo uma importante causa de morbidade e mortalidade. Em alguns países, o CE ainda é a principal causa de morte por acidente em crianças abaixo de um ano de idade ${ }^{1}$.

Logo após a aspiração de material estranho, a criança pode apresentar tosse intensa, sibilância, vômito, palidez, cianose ou episódios breves de apnéia. Após essas manifestações dramáticas iniciais, o quadro clínico geralmente se atenua, ou mesmo desaparece completamente. Este peque- 
no intervalo de tempo em que a criança não apresenta sintomatologia exuberante pode dar a falsa impressão ao observador de que o CE possa ter sido expelido através da tosse, ou mesmo deglutido. Daí a importância do médico estar sempre atento a esta possibilidade diagnóstica ${ }^{2}$.

$\mathrm{O}$ tratamento para crianças com aspiração de CE é a retirada endoscópica com equipamento rígido ou flexível. Entretanto, em situações raras, alguns materiais não podem ser retirados por endoscopia, tendo os mesmos que serem removidos por alguma abertura da via aérea. Revisão realizada por Marks et al. ${ }^{3}$, com estudo de 6.393 pacientes com CE da via aérea, mostrou que, quando há indicação de cirurgia aberta para remoção de $\mathrm{CE}$, é mais comum a necessidade de toracotomia $(2,5 \%)$ do que traqueostomia (2\%). Dos 104 pacientes que necessitaram traqueostomia, 52 foram por edema laríngeo após broncoscopia, 12 como via de introdução do broncoscópio, 11 para permitir ventilação assistida, e somente 10 para permitir a retirada de materiais volumosos que não passavam na região subglóti$\mathrm{ca}^{3}$. Em 19 pacientes, não foi comentada a indicação da traqueostomia ${ }^{3}$. É importante observar que a indicação de traqueotomia para remover $\mathrm{CE}$ traqueobrônquico, como descrita em um de nossos pacientes, é relatada em apenas 11 casos da literatura ${ }^{3,4}$, sugerindo que este é um evento extremamente raro. Apesar deste nosso paciente já ter sido relatado em publicação internacional prévia ${ }^{4}$, julgamos importante a inclusão do mesmo nesta série de casos, pois, embora raramente necessária, é importante que o médico que remova $\mathrm{CE}$ da via aérea de criança esteja familiarizado com a possibilidade de traqueotomia, a fim de que ela possa ser realizada quando necessário.

Como a região subglótica é o local mais estreito da via aérea da criança, qualquer edema provocado pela passagem de CE calibroso neste local pode diminuir ainda mais o calibre desta área, e impossibilitar a nova passagem do CE durante sua retirada. Este é um momento dramático durante a realização do procedimento endoscópico, pois o CE que não passa na região subglótica obstrui completamente a traquéia, com conseqüente hipoxemia, bradicardia e parada cardíaca. Antes da ocorrência deste evento catastrófico, é importante que o cirurgião empurre o CE com o broncoscópio para um dos brônquios principais, a fim de permitir a ventilação de no mínimo um dos pulmões. Esta manobra é fundamental e salvadora.

Durante a remoção de CE traqueobrônquico, a retirada do mesmo por abertura traqueal está indicada quando o $\mathrm{CE}$ é demasiadamente largo e não passa na região subglótica, como o observado em um de nossos pacientes. Outras indicações de abertura traqueal são remoção de CE pontiagudos, cujas pontas trancam na subglote ou nas cordas vocais, e quando o CE impacta na região subglótica e provoca uma obstrução aguda ${ }^{3-5}$. Também em pacientes com prévia traqueostomia, como os referidos neste estudo, a introdução de equipamento endoscópico pela traqueostomia facilita a retirada de grandes materiais aspirados para a via aérea.
Quando a remoção de $\mathrm{CE}$ da via aérea requerer a abertura traqueal, é importante a atuação de duas equipes treinadas: uma para a abordagem cervical, abertura traqueal e remoção do CE sob visão direta; e a outra para realizar a broncoscopia, apreensão e tração do $\mathrm{CE}$ até a região da traqueotomia. A atuação sincronizada destas equipes, em um curto período de tempo, é fundamental para a remoção do CE e permitir a ventilação adequada da criança.

Relatos na literatura descrevem a necessidade de realização de traqueostomia após a traqueotomia para remoção de CE da via aérea. Entretanto, isto não é uma indicação absoluta de traqueostomia, como pôde ser evidenciado em um de nossos pacientes. Se for possível a realização de uma sutura traqueal firme e sem vazamento, é necessário apenas a manutenção da intubação traqueal por dois a cinco dias. Isto é o tempo suficiente para reduzir o edema local e permitir uma extubação segura ${ }^{4}$.

A aspiração para a via aérea de parte fraturada de cânula de traqueostomia é um evento incomum ${ }^{6}$. O primeiro caso de aspiração de cânula traqueal metálica fraturada foi em $1960^{7}$; a aspiração de porções de cânula de PVC (Portex ${ }^{\circledR}$ ) foi relatada em uma criança por $\operatorname{Sood}^{8}$, e em três outras crianças por Bhatia e colaboradores ${ }^{9}$. A aspiração descrita aqui é o terceiro relato publicado na literatura. Em todas as crianças, como referido em nosso paciente, a fratura da cânula ocorreu na união entre o tubo e a placa horizontal utilizada para fixação da cânula no pescoço ${ }^{6}$. Os autores atribuem a quebra da cânula ao uso prolongado ou a defeito na conexão do tubo da traqueostomia, com a parte horizontal externa utilizada para fixação cervical. Embora as cânulas de PVC (Portex $\left.{ }^{\circledR}\right)$ não apresentem emendas nesta região, o desgaste propicia ocorrência de fratura ${ }^{6}$.

Concluimos que uma minoria de $\mathrm{CE}$ aspirados para a via aérea da criança não podem ser removidos somente por endoscopia, mesmo quando a mesma é realizada por cirurgião experiente. A realização concomitante de traqueotomia, ou mesmo a utilização de traqueostomia realizada previamente, está indicada em pacientes que aspiraram CE demasiadamente largos, que não passam na região subglótica, CE pontiagudos, cujas pontas trancam na subglote ou nas cordas vocais, ou CE que impactam na região subglótica e provocam obstrução ventilatória aguda.

\section{Referências bibliográficas}

1. Black RE, Choi KJ, Syme WC, Johnson DG, Matlak ME. Bronchoscopy removal of aspirated foreign bodies in children. Am J Surg 1984;148(6):778-81.

2. Hughes CA, Baroody FM, Marsh BR. Pediatric tracheobronchial foreign bodies: historical review from the Johns Hopkins Hospital. Ann Otol Rhinol Laryngol 1996;105(7):555-61.

3. Marks SC, Marsh BR, Dudgeon DL. Indications for open surgical removal of airway foreign bodies. Ann Otol Rhinol Laryngol 1993;102:690-4. 
4. Fraga JC, Neto AM, Seitz E, Schopf L. Bronchoscopy and tracheotomy removal of bronchial foreign body. J Pediat Surg 2002;37(8):1239-40.

5. Swensson EE, Rah KH, Kim MC, Brooks JW, Salzberg AM. Extraction of large tracheal foreign body through a tracheostomy under bronchoscopic control. Ann Thorac Surg 1985;39(3):251-3.

6. Ng DK, Cherk SW, Law AK. Flexible fiberoptic bronchoscopic removal of a fractured synthetic tracheostomy tube in a 3-yeardold child. Pediatr Pulmonol 2002;34:141-3.

7. Bassoe HH, Boe J. Broken tracheostomy tube as a foreign body. Lancet 1960;1:1006-1007.

8. Sood RK. Fractured tracheostomy tube. J Laryngol Otol 1973;87:1033-4.
9. Bhatia S, Malik MK, Bhatia BP. Fracture of tracheostomy tubes - report of 3 cases. Indian J Chest Dis Allied Sci 1992;34:111-3.

\section{Endereço para correspondência}

Dr José Carlos Fraga

Rua Ramiro Barcelos, 2350 - sala 600 (6 $6^{\circ}$ andar)

CEP 90430-000 - Porto Alegre, RS

Tel.: (51) 3316.8232

E-mail: jcfraga@brturbo.com 